\title{
Increasing incidence rates, distribution and histological characteristics of primary gastrointestinal non-Hodgkin lymphoma in a North American population
}

\author{
JM Howell MD MSc ${ }^{1}$, I Auer-Grzesiak MD¹, J Zhang PhD², CN Andrews MD MSc ${ }^{3}$, D Stewart MD ${ }^{4}, \mathrm{SJ}_{\text {Urbanski MD }}^{1}$
}

\begin{abstract}
JM Howell, I Auer-Grzesiak, J Zhang, CN Andrews, D Stewart, SJ Urbanski. Increasing incidence rates, distribution and histological characteristics of primary gastrointestinal nonHodgkin lymphoma in a North American population. Can J Gastroenterol 2012;26(7):452-456.
\end{abstract}

BACKGROUND: The incidence of primary extranodal non-Hodgkin lymphoma (NHL) of the gastrointestinal (GI) tract has been on the rise.

OBJECTIVES: To determine the incidence of primary GI NHL and distribution according to site and histological type in a large North American adult population over a 10 -year period.

METHODS: All diagnoses of GI NHL made between January 1999 and January 2009 were reviewed using a regional pathology database. Patients $\geq 18$ years of age living within health region boundaries were included. Age- and sex-adjusted incidence rates of GI NHL according to GI site and histological type over a 10-year period were calculated and compared.

RESULTS: A total of 149 cases of primary GI NHL were identified during the study period. Age- and sex-adjusted yearly incidence rates ranged from 0.13 per 100,000 in 1999 , to 2.39 per 100,000 in 2007. Histological distribution (47\% diffuse large B cell lymphoma, 24\% extranodal marginal zone lymphoma of mucosa-associated lymphoid tissue type, $8 \%$ follicular and 5\% mantle cell) and site distribution (47\% stomach, 26\% small bowel, 17\% colon) were obtained with increasing annualized incidence rates for each of these sites over time. Remaining cases included multiple GI sites of involvement (9\%) and esophagus $(0.7 \%)$.

DISCUSSION: Population-based GI NHL incidence rates in the present study were higher than those described elsewhere in North America and Europe. Nearly one-half showed high-grade (diffuse large B cell lymphoma) histology at diagnosis. Incidence rates for the colon exceed those described in other studies worldwide.

CONCLUSION: Because the majority of GI NHL are diagnosed on endoscopic biopsy, clinicians and pathologists must be vigilant of this entity.

Key Words: Extranodal non-Hodgkin lymphoma; Gastrointestinal tract; Incidence

$\mathrm{M}$ alignant non-Hodgkin lymphoma (NHL) has been increasing in incidence worldwide; this trend also applies to cases of primary extranodal NHL - cases of NHL arising outside of the lymph nodes, notably the gastrointestinal (GI) tract (1). The GI tract is among the most common sites for NHL arising extranodally (2). GI NHL is an entity that has been increasing in incidence and mortality, particularly in westernized countries $(3,4)$. Canada has NHL rates among the highest in the world, with incidence rates doubling since the 1970s (5). GI NHL has correspondingly been increasing in incidence in Canada. A
Les taux d'incidence croissants, la répartition et les caractéristiques histologiques du lymphome non hodgkinien primitif du tube digestif au sein d'une population nord-américaine

HISTORIQUE : L'incidence de lymphomes non hodgkiniens (LNH) extranodaux primitifs du tube digestif (TD) augmente.

OBJECTIFS : Déterminer l'incidence de LNH primitifs du TD d'après le foyer et le type histologique sur une période de dix ans, dans une vaste population nord-américaine d'adultes.

MÉTHODOLOGIE : Les chercheurs ont analysé tous les LNH du TD tirés d'une base de données pathologique régionale et diagnostiqués entre janvier 1999 et janvier 2009. Ils ont inclus les patients de 18 ans ou plus qui habitaient dans les limites de la régie régionale. Ils ont calculé et comparé les taux d'incidence de LNH du TD rajustés selon l'âge et selon le sexe d'après le foyer du TD et le type histologique, et ce, sur une période de dix ans.

RÉSULTATS : Au total, les chercheurs ont dépisté 149 cas de LNH primitif du TD pendant la période de l'étude. Les taux d'incidence annuels rajustés selon l'âge et selon le sexe se situaient entre 0,13 cas pour 100000 habitants en 1999 et 2,39 cas pour 100000 habitants en 2007. Les chercheurs ont colligé la répartition histologique (47\% de lymphomes diffus à grandes cellules B, $24 \%$ de lymphomes extranodaux de la zone marginale des tissus lymphoïdes associés aux muqueuses, $8 \%$ de lymphomes folliculaires et $5 \%$ de lymphomes du manteau) et la répartition dans les divers foyers (47\% dans l'estomac, $26 \%$ dans le grêle, $17 \%$ dans le côlon) et constaté des taux d'incidence annualisés croissants dans chacun de ces foyers au fil du temps. Les autres cas incluaient une atteinte de divers foyers du TD (9\%) et une atteinte de l'œsophage (0,7 \%).

EXPOSÉ : Les taux d'incidence de LNH du TD en population constatés dans la présente étude étaient plus élevés que ceux décrits ailleurs en Amérique du Nord et en Europe. Près de la moitié présentaient un haut grade de malignité sur le plan histologique (lymphomes diffus à grandes cellules B) au diagnostic. Les taux d'incidence dans le côlon sont supérieurs à ceux décrits dans les autres études ailleurs dans le monde. CONCLUSION : Puisque la majorité des LNH du TD sont diagnostiqués par biopsie endoscopique, les cliniciens et les pathologistes doivent demeurer vigilants à l'égard de cette entité.

recent study involving a North American adult population between 1999 and 2003 demonstrated a population-based incidence rate of primary extranodal GI NHL of 1.73 per 100,000, higher than in other parts of the western world (6).

Associated risk factors for primary GI NHL include Helicobacter pylori infection, celiac disease and immunosuppression (eg, following solid organ transplantation or HIV infection) (7). Most GI NHLs are of mature B cell origin; however, $\mathrm{T}$ cell lymphomas are also found in the GI tract, usually seen in association with celiac disease in the small

\footnotetext{
${ }^{1}$ Department of Anatomical Pathology; ${ }^{2}$ ephrology Research Group; ${ }^{3}$ Division of Gastroenterology; ${ }^{4}$ Divisions of Hematology and Medical Oncology,

University of Calgary, Calgary, Alberta

Correspondence: Dr Jenika Howell, Department of Anatomical Pathology, University of Calgary, 1403-29 Street Northwest, Calgary, Alberta T2N 2T9.

Telephone 403-944-4751, fax 403-944-1460, e-mail jenika.howell@cls.ab.ca

Received for publication February 16, 2011. Accepted September 18, 2011
} 
bowel (8). Mature B and T cell lymphomas are those that have differentiated from their precursor forms in the bone marrow (B cell) and thymus ( $\mathrm{T}$ cell), have homed to the GI tract and have undergone malignant transformation. Both histology and immunohistochemistry are required to render a specific diagnosis.

The aim of the present study was to determine the characteristics of GI NHL over a 10-year period within an adult North American population, including incidence, age and sex distribution, histological classification and specific sites of involvement along the GI tract.

\section{METHODS}

\section{Study population}

The Calgary Health Region (CHR, now part of Alberta Health Services) includes the city of Calgary (Alberta), with a population of more than one million, as well as several other surrounding communities with a total population of 1,285,972 in 2008 (9). Ethnic make-up of the CHR includes approximately $80 \%$ white, $10 \%$ Asian and 3\% Aboriginal, with the remaining population comprised of various other ethnicities (10).

\section{Study protocol and case definitions}

Diagnoses of all GI NHLs made between January 1, 1999 and January 2009 were obtained from the entire Calgary Lab Services (CLS) database, using the search terms "lymphoma" and "malignant lymphoma". The CLS database is a centralized database of all histopathological diagnoses made at any site in the CHR, including surgical pathology, cytology and autopsy results. Criteria applied in selecting cases included age $\geq 18$ years at diagnosis, current inhabitants of the CHR at diagnosis and clear specification of primary GI NHL occurring from the esophagus to anus. A total of 325 potential cases of primary GI NHL were identified over the study period. On closer examination of pathology reports and cross-referencing with the Alberta Cancer Board (ACB) database, 176 cases did not meet the specific criteria listed above. For example, some of the cases were designated 'mesenteric mass'. Alternatively, some of the 325 identified cases represented repeat biopsies on the same patient and, thus, only the original diagnosis of GI NHL was included in the analysis. Cases in question as to site or demographic information were cross-referenced using the ACB database (DS). The Alberta Cancer Registry (ACR) is a populationbased registry for all new cancer cases occurring in the province of Alberta. Aggregate data on the incidence of primary GI NHL according to site and histological type were also obtained from the ACR for comparison.

All histopathological diagnoses made on cases not initially reviewed by a lymphoma pathologist were verified by an expert lymphoma pathologist (IAG). Of these cases, fewer than $5 \%$ of original diagnoses rendered were either reclassified under a different lymphoma histopathological type or were deemed not to be lymphoma. The main categories in the analysis included diffuse large B cell lymphoma (DLBCL), extranodal marginal zone lymphoma of mucosa-associated lymphoid tissue (MALT) (marginal/MALT), follicular, mantle cell, Burkitt lymphoma, B cell lymphoma not otherwise specified (BCLNOS), enteropathy-associated T cell lymphoma, post-transplant lymphoproliferative disorders, lymphomas arising in a background of other malignancies (eg, carcinoma) and natural killer/T cell (NK-T) lymphoma. All of these histological subtypes, with the exception of lymphomas arising in a background of other malignancies, are recognized in the WHO lymphoma classification (8). In general, the diagnosis of malignant lymphomas was based on hematoxylin and eosin-stained tissue sections obtained from biopsy material or resection specimens with immunohistochemistry for $\mathrm{B}$ and $\mathrm{T}$ cell markers. Lymphomas were also divided based on site of occurrence (esophagus, stomach, small bowel, large bowel, multiple sites), where multiple sites corresponded to more than one anatomic area, for instance colon + small bowel, or stomach + small bowel.

Statistical analysis

Statistical analysis was performed using STATA version 10.1 (STATA
TABLE 1

Study demographics $(n=149)$

\begin{tabular}{lcc}
\hline & Male:female & $\mathbf{n}(\%)$ \\
\hline Male & & $89(60)$ \\
Female & & $60(40)$ \\
Age, years, mean (range) & & $63.8(22-90)$ \\
Lymphoma subtype & & \\
$\quad$ Diffuse large B cell lymphoma & $1.6: 1$ & $70(47)$ \\
Marginal/mucosa-associated lymphoid tissue & $1.2: 1$ & $35(23)$ \\
Follicular & $1: 2$ & $12(8)$ \\
Mantle cell & $1.3: 1$ & $7(5)$ \\
Burkitt & $2.5: 1$ & $7(5)$ \\
B cell lymphoma not otherwise specified & $3: 1$ & $4(3)$ \\
Enteropathy-T & $4: 0$ & $4(3)$ \\
Post-transplant lymphoproliferative disorder & $4: 1$ & $5(3)$ \\
Coexisting with other malignancies & $1: 1$ & $4(3)$ \\
Natural killer T cell & $1: 0$ & $1(0.7)$ \\
Site along gastrointestinal tract & & \\
Esophagus & $0: 1$ & $1(0.7)$ \\
Stomach & $1.5: 1$ & $70(47)$ \\
Small bowel & $1.8: 1$ & $39(26)$ \\
Colon & $1.4: 1$ & $26(17)$ \\
Multiple sites & $1.2: 1$ & $13(9)$ \\
\hline
\end{tabular}

Corporation, USA) (JZ). The crude and age- and sex-standardized incidence rates according to site of the lymphoma (stomach, small bowel, etc) and according to lymphoma type over a 10-year period (January 1999 to 2009) were obtained. The standardized incidence rates were calculated using a direct standardization method using the 1999 Calgary population $\geq 18$ years of age as the standard population. The $95 \%$ CIs were estimated based on the gamma distribution as proposed by Fay and Feuer (11). This method produces valid CIs even when the number of cases is very small. The size and demographic profile of the CHR was obtained from the Interactive Health Data Application through the government of Alberta (9). In 1999, the CHR population at risk ( $\geq 18$ years of age) was 81,1977 .

\section{Incidence and demographics}

\section{RESULTS}

Demographics data are presented in Table 1. A total of 149 cases collected between January 1999 and January 2009 were identified as primary GI NHL. On average, age at diagnosis was 63.8 years, with more than $75 \%$ of cases occurring after 55 years of age. The majority of extranodal GI NHL occurred in the stomach (47\% of all cases), with small bowel (26\%), colon (17\%), multiple sites (9\%) and esophagus $(0.7 \%)$ comprising the remaining cases (Table 1, Figure 1A).

There was an overall male to female ratio of $1.5: 1$ when taking into account all GI NHL cases over the 10-year study period. Increased male relative to female ratios held for all histopathological subtypes with the exception of follicular lymphoma (male to female ratio of $1: 2$ ). Approximately equal male to female ratios were obtained for marginal/MALT lymphoma (1.2:1), mantle cell (1.3:1) and lymphomas occurring in a background of another unrelated malignancy $(1: 1)$ (Table 1). Male to female ratio of distribution of lymphoma according to site demonstrated the largest ratio differences along the small bowel (1.8:1), followed by stomach (1.5:1), colon (1.4:1) and multiple GI sites (1.2:1) (Table 1).

Age- and sex-adjusted incidence rates of GI NHL according to site are illustrated in Figure 1B. In all instances, with the exception of esophagus, in which only one case in 10 years was found, the annual incidence rates of GI NHL according to site increased over time (Figure 1B).

Histopathology and distribution along the GI tract

Overall, histological classification of all 149 cases of GI NHL showed 47\% DLBCL; 23\% marginal/MALT lymphoma; $8 \%$ follicular; $5 \%$ for 


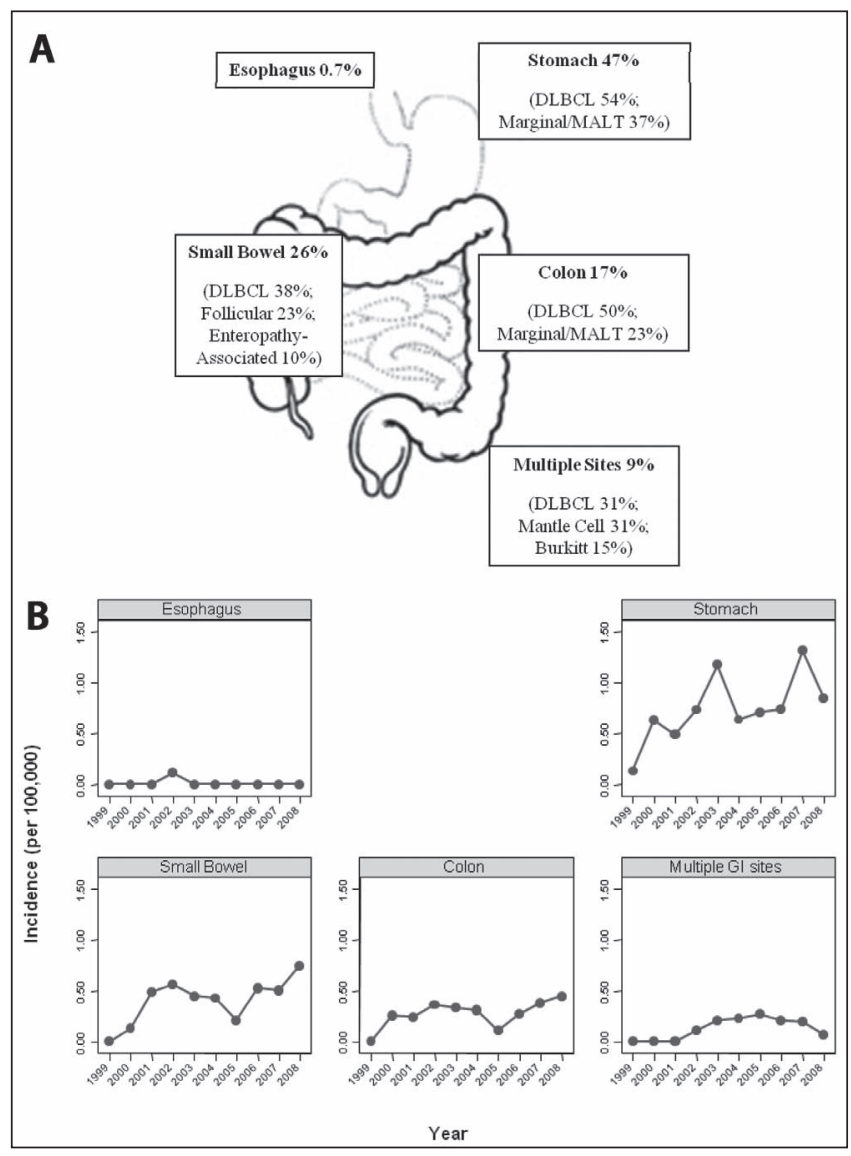

Figure 1) A Overall per cent distribution of primary gastrointestinal (GI) non-Hodgkin lymphoma (GI NHL) according to site along the GI tract. The most common histological types (\%) found at each site are listed. B Variations in age- and sex-standardized GI NHL incidence rates (per 100,000) according to site along the GI tract from 1999 to 2009. DLBCL Diffuse large B cell lymphoma; MALT Mucosa-associated lymphoid tissue

each of mantle cell and Burkitt lymphoma; and 3\% for each of BCLNOS, enteropathy-associated $\mathrm{T}$ cell lymphoma, post-transplant lymphoproliferative disorders and lymphomas coexisting with other malignancies. Only $0.7 \%$ comprised NK-T cell lymphoma histology (Table 1, Figure 2A).

The per cent distribution of GI NHL cases according to site and histological type along the GI tract is presented in Figures 1A and 2, and Table 2. Within the stomach, the main histological subtype was DLBCL (54\%), followed by marginal/MALT zone (37\%). The small bowel showed a majority of DLBCL (38\%), followed by follicular (23\%) and included all cases of enteropathy-associated T cell lymphoma (10\%). All of the patients diagnosed with enteropathy-associated T cell lymphoma were known to have celiac disease. The colon demonstrated a majority of DLBCL (50\%), followed by marginal/MALT zone $(23 \%)$. Multiple GI sites involving lymphoma showed histological subtypes in the form of DLBCL and mantle cell (31\% each), with $15 \%$ of cases comprised of Burkitt lymphoma (Figures $1 \mathrm{~A}$ and 2, Table 2).

When considering all 149 cases, the overall age- and sex-adjusted incidence rates of primary GI NHL within the study population showed a statistically significant increase over time from January 1999 to January 2009. There was a steady increase in the incidence of GI NHL from 1999 to 2003, followed by a dip between 2003 and 2005, and, finally, a rising incidence between 2005 and 2008, with a maximum of 2.39 per 100,000 in 2007 (Figure 3).
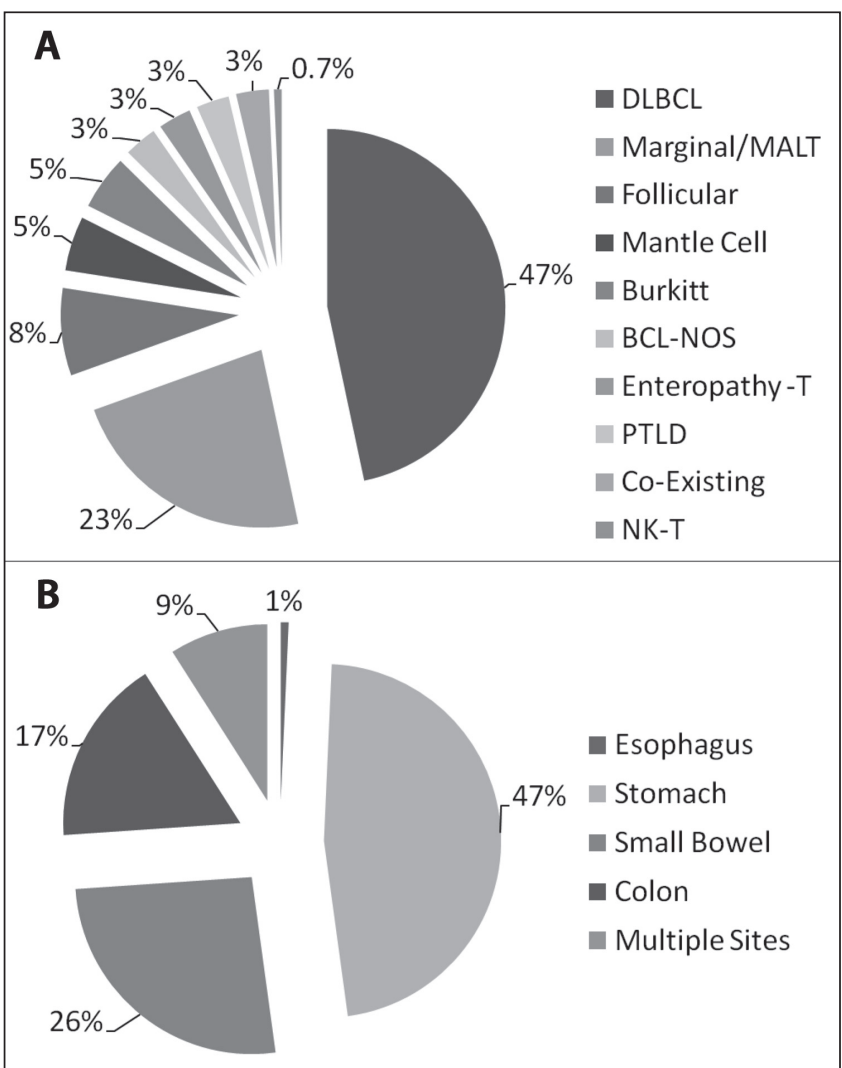

Figure 2) A Per cent distribution of diagnosed primary gastrointestinal (GI) non-Hodgkin lymphoma (GI NHL) according to histology during the study period. B Per cent distribution of primary GI NHL according to site along the GI tract during the study period. BCL-NOS B cell lymphoma not otherwise specified; DLBCL Diffuse large B cell lymphoma; MALT Mucosa-associated lymphoid tissue; NK-T Natural killer T cell; PTLD Post-transplant lymphoproliferative disorder

\section{DISCUSSION}

The results of the present study demonstrated an overall increase in the incidence of GI NHL from 0.13 per 100,000 to 2.10 from January 1, 1999 to January 1, 2009. The age- and sex-adjusted incidence of GI NHL exceeded the rates published in various population-based studies from around the world (Table 3). GI NHL incidence according to site for the stomach, small bowel and colon demonstrated a general increase over the study period (Figure 1B). Incidence rates for primary colonic NHL were higher than expected $(0.25$ per 100,000 in 2000 , climbing to 0.45 per 100,000 in 2008). This incidence is nearly fivefold greater than American rates of colonic GI NHL from the 1990s (12).

The overall number of GI NHLs with high-grade histology (ie, DLBCL) comprised nearly $50 \%$ of the 149 cases $(n=70)$, whereas less aggressive histology (marginal/MALT) comprised 23\% of cases (Table 1). In terms of lymphoma distribution according to histological type, DLBCL was the most common for each location along the GI tract (Figure 1A). The next most common histological types were marginal/MALT lymphoma in the stomach and colon, follicular lymphoma in the small bowel and mantle cell lymphoma at multiple sites (Table 2, Figures 1A and 2A). This trend of increased DLBCL relative to other histologies coincides with results found in other studies worldwide, in which the histological subtype of GI NHL was predominantly high grade (DLBCL) regardless of site along the GI tract $(6,13,14)$. However, our results differed from d'Amore et al $(15)$, in which the majority of gastric NHL was of the marginal/MALT type, and Papaxoinis et al (16), in which the proportion of marginal/MALT zone and DLBCL were approximately equal. Reasons for this trend remain unclear, although geographic and ethnic differences may be implicated (12). 
TABLE 2

Primary gastrointestinal (GI) non-Hodgkin lymphoma cases according to $\mathrm{GI}$ site and histological type

\begin{tabular}{|c|c|c|c|}
\hline & \multirow[b]{2}{*}{$\mathbf{n}$} & \multicolumn{2}{|c|}{$\%$} \\
\hline & & $\begin{array}{c}\text { According to } \\
\text { site }\end{array}$ & $\begin{array}{l}\text { Overall } \\
(n=149)\end{array}$ \\
\hline \multicolumn{4}{|l|}{ Esophagus $(n=1)$} \\
\hline BCL-NOS & 1 & & 0.7 \\
\hline \multicolumn{4}{|l|}{ Stomach $(n=70)$} \\
\hline DLBCL & 38 & 54 & 26 \\
\hline Marginal/MALT & 26 & 37 & 17 \\
\hline Mantle cell & 2 & 3 & 1 \\
\hline BCL-NOS & 1 & 1 & 0.7 \\
\hline Coexisting other malignancies & 3 & 4 & 2 \\
\hline \multicolumn{4}{|l|}{ Small bowel (n=39) } \\
\hline DLBCL & 15 & 38 & 10 \\
\hline Marginal/MALT & 2 & 5 & 1 \\
\hline Follicular & 9 & 23 & 6 \\
\hline Burkitt & 3 & 8 & 2 \\
\hline BCL-NOS & 1 & 3 & 0.7 \\
\hline Enteropathy-T & 4 & 10 & 3 \\
\hline PTLD-related & 3 & 8 & 2 \\
\hline Coexisting other malignancies & 1 & 3 & 0.7 \\
\hline NK-T & 1 & 3 & 0.7 \\
\hline \multicolumn{4}{|l|}{ Colon $(n=26)$} \\
\hline DLBCL & 13 & 50 & 9 \\
\hline Marginal/MALT & 6 & 23 & 4 \\
\hline Follicular & 2 & 8 & 1 \\
\hline Mantle cell & 1 & 4 & 0.7 \\
\hline Burkitt & 2 & 8 & 1 \\
\hline BCL-NOS & 1 & 4 & 0.7 \\
\hline PTLD related & 1 & 4 & 0.7 \\
\hline \multicolumn{4}{|l|}{ Multiple GI sites ( $n=13$ ) } \\
\hline DLBCL & 4 & 31 & 3 \\
\hline Marginal/MALT & 1 & 8 & 0.7 \\
\hline Follicular & 1 & 8 & 0.7 \\
\hline Mantle cell & 4 & 31 & 3 \\
\hline Burkitt & 2 & 15 & 1 \\
\hline PTLD related & 1 & 8 & 0.7 \\
\hline
\end{tabular}

$B C L-N O S$ B cell lymphoma not otherwise specified; DLBCL Diffuse large $B$ cell lymphoma; MALT Mucosa-associated lymphoid tissue; NK-T Natural killer $T$ cell; PTLD Post-transplant lymphoproliferative disorder

In the present study, age-adjusted sex ratios of GI NHL according to site (stomach 1.5:1; small intestine 1.8:1; colon 1.4:1) do not appear to differ overtly from those obtained from United States data (1.4:1; $1.8: 1 ; 2.2: 1$, respectively) (12). Moreover, the male to female ratios for all cases of GI NHL in the present study was $1.5: 1$, the same ratio obtained from American whites for extranodal lymphomas of all types combined (12). Whether increasing incidences of GI NHL are due to enhanced detection methods, better case registration, host factors (ie, $H$ pylori infection, solid organ transplantation) or a combination thereof remains unclear (17). The association of $H$ pylori with NHL has been known for several years, and treatment has not necessarily resulted in a decreased incidence of gastrointestinal marginal/MALT lymphomas and DLBCLs. Various explanations, including genetic alterations to the tissue (ie, t $[11 ; 18]$ q $[21 ; 21]$ ), have been proposed (for a review, see Saegart et al [18]).

Primary GI follicular lymphoma is rare. Of the few published studies, including data from the United States, France and Taiwan (19-22), all have shown a preponderance of follicular lymphoma for the small bowel, and an approximately 2:1 female to male ratio, results that are further supported by the present study. At presentation, primary GI follicular lymphomas tend to be indolent and are frequently diagnosed

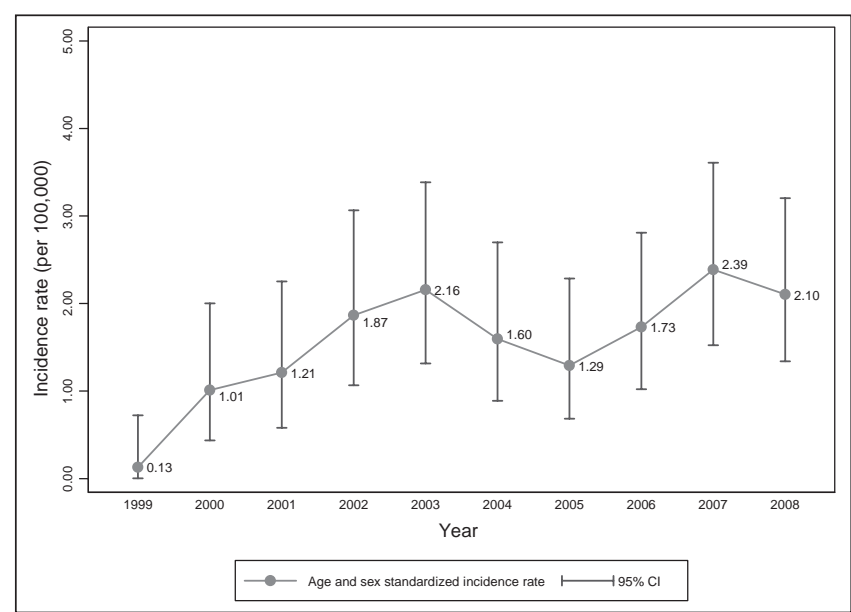

Figure 3) Age- and sex-standardized incidence rate of primary gastrointestinal non-Hodgkin lymphoma over time (per 100,000)

\section{TABLE 3}

Summary of primary gastrointestinal non-Hodgkin lymophoma incidence rates from various studies

\begin{tabular}{|c|c|c|c|}
\hline Author (reference), year & Country & Study period & Incidence, $\times 10^{5}$ \\
\hline d'Amore et al (15),1994 & Denmark & 1983-1991 & 1.19 \\
\hline Halme et al (3), 1997 & Finland & 1975-1993 & 1.25 \\
\hline Newton et al (12), 1997 & United States & 1978-1987 & 0.69 (whites) \\
\hline Gurney et al (13), 1999 & England \& Wales & 1986-1993 & 0.58 \\
\hline Andrews et al (6), 2008 & Canada & 1999-2003 & 1.73 \\
\hline
\end{tabular}

at a low stage (IE or IIE), with an overall excellent prognosis, whereas in primary nodal follicular lymphoma, presentation tends to be significantly more advanced, with approximately one-third of patients at stage I or II at diagnosis, and bone marrow involvement in $40 \%$ to $70 \%$ of cases (8). Additional data were obtained from seven of the follicular lymphoma cases, with three found to be at stage IAE at the time of diagnosis. One patient had since died from their disease and three of seven had relapsed following initial treatment.

The usual sites of extranodal GI NHLs include the stomach (most common), small bowel and large bowel (least common). Gastric GI NHL accounts for $>50 \%$ of all primary GI NHLs, and is associated with chronic $H$ pylori infection. Although initially the resulting lymphoma may be of low-grade marginal/MALT type, transformation to higher-grade DLBCL with time can occur if untreated. As a site for GI NHL, the small bowel is the next most common location, accounting for an estimated $30 \%$ primary GI NHL, with the ileum accounting for most cases, postulated to be secondary to the number of Peyer's patches present in this region. The large bowel comprises approximately $10 \%$ of primary extranodal GI NHLs, and are mostly of B cell origin. Rectal, appendiceal and esophageal primary GI NHLs are relatively rare (7). These general trends are also reflected in the present work.

We made an effort to rigorously assess histopathology reports to ensure that specimens were confirmed cases of primary GI NHL, as well as cross-referencing cases to separate databases (ACB, ACR). Aggregate data independently obtained through the ACR from 1999 to 2008 closely mirrored and supported the findings of the present study. A total of 140 cases of primary GI NHL were documented through the ACR during this time period (present study: 149 cases from 1999 to 2009). Overall, ACR data showed an increasing number of GI NHL cases between 1999 (10 cases) and 2008 (21 cases). Distribution along the GI tract showed 52.1\% stomach, 29.3\% small intestine, $15.0 \%$ colon (present study: $47 \%, 26 \%$ and $17 \%$, respectively). In terms of histology, $48.6 \%$ of cases corresponded to DLBCL, $22.1 \%$ marginal/MALT and $8.6 \%$ follicular (present study: 47\%, 23\% and $8 \%$, respectively). Furthermore, the review of all diagnoses not 
initially rendered by an expert lymphoma pathologist ensured correct histological subtyping. Results from the present study closely followed the age and sex characteristics of nodal NHL as outlined in the most recent WHO lymphoma classification (8).

In 2008 (ie, during the study period), a new colon cancer screening program was established within the $\mathrm{CHR}$, which resulted in a nearly twofold increase in the number of endoscopies performed. However, this did not appear to have affected detection rates because a decrease in incidence of extranodal GI NHL was observed (Figure 3). Small intestinal capsule endoscopy and small bowel enterography are methods of detection currently used in Calgary. The degree to which these have led to an increased detection in small bowel lymphoma is unknown; thus, the increased incidence in GI NHL may, in part, be due to the use of these methodologies. The limitations of the present work, shared by many other studies, include the fact that the ability to distinguish cases of true primary GI NHL is difficult in that all extranodal disease may not have been accounted for. Moreover, in some cases, it may not be possible to distinguish a lymph node infiltrating into an adjacent GI tract.

This information highlights the need for clinicians to be ever vigilant of the possibility of primary GI NHL, especially at a colonic location. Lymphomas of the GI tract may mimic carcinoma in terms of their gross appearance. Moreover, there is a broad range of presentations both from an imaging and endoscopic perspective. GI NHLs of various histological subtypes may manifest as mucosal thickening, single polyps, lymphomatous polyposis, ulcerating bulky masses or diffuse infiltration $(7,23,24)$. Complications can include obstruction, perforation and fistulization. The importance of proper sampling of these lesions cannot be overemphasized. Pathologists should also consider this diagnosis and should be prepared to submit tissue for lymphoma studies to ensure proper subtyping and characterization of the lesions. Additional work is required to correlate cases with risk factors, such as celiac disease, inflammatory bowel disease, $\mathrm{H}$ pylori and underlying immunosuppression, which are often not included in patient history, diagnoses or microscopic descriptions on the pathology report.

ACKNOWLEDGEMENTS: The authors are indebted to Dr Noel Hershfield, who brought our attention to the increasing frequency of GI lymphomas in his practice, therefore prompting this investigation.

What is the current knowledge?:

\section{KEY MESSAGES}

- The GI tract is the most common extranodal site for NHL.

- Primary GI NHL has been increasing in incidence worldwide.

- Endoscopic presentation of these lesions can vary.

What is new here:

- A population-based study undertaken within the CHR (1999 to 2009) shows an increase in incidence of primary GI NHL, at rates higher than Europe and other areas within North America.

- All sites along the GI tract, with the exception of esophagus, show an increase in incidence of GI NHL.

- There are differing lymphoma histologies at various sites along the GI tract.

- High-grade lymphoma, specifically DLBCL, comprised nearly $50 \%$ of all cases of GI NHL, and was the most common histology found at each site along the GI tract. This suggests factors other than $\mathrm{H}$ pylori are likely responsible for this phenomenon.

- Clinicians and pathologists alike must be aware of the increased possibility of primary GI NHL, especially in the context of colon cancer screening programs and improved detection methods, including intestinal capsule endoscopy as well as small bowel enterography.

\section{REFERENCES}

1. Liu S, Semenciw R, Mao Y. Increasing incidence of non-Hodgkin's lymphoma in Canada, 1970-1996: Age-period-cohort analysis. Hematol Oncol 2003;21:57-66.

2. Crump M, Goapodarowicz M, Shepherd FA. Lymphoma of the gastrointestinal tract. Semin Oncol 1999;26:324-337.

3. Halme L, Mecklin J-P, Juhola M, Krees R, Palmu A. Primary gastrointestinal non-Hodgkin's lymphoma: A population based study in central Finland in 1975-1993. Acta Oncol 1997;36:69-74.

4. Gurney KA, Cartwright RA. Increasing incidence and descriptive epidemiology of extranodal non-Hodgkin lymphoma in parts of England and Wales. Hematology 2002;3:90-104.

5. National Cancer Institute of Canada (NCIC). Canadian Cancer Statistics 2001. Toronto: NCIC, 2001:15-47.

6. Andrews CN, Gill MJ, Urbanski SJ, Stewart D, Perini R, Beck P. Changing epidemiology and risk factors for gastrointestinal nonHodgkin's lymphoma in a North American population: Population-based study. Am J Gastroenterol 2008;103:1762-9.

7. Ghai S, Pattison J, Ghai S, O'Malley ME, Khalili K, Stephens M. Primary gastrointestinal lymphoma: Spectrum of imaging findings with pathologic correlation. Radiographics 2007;27:1371-88.

8. World Health Organization Classification of Tumours of Haematopoietic and Lymphoid Tissues. Swerdlow SH, Campo E, Harris NL, Jaffe ES, et al, eds. World Health Organization Classification of Tumours Pathology and Genetics: Tumours of Haematopoietic and Lymphoid Tissues. Lyon, France: IARC Press, 2008.

9. Alberta Health and Wellness Census Data: Demographics. <www.ahw.gov.ab.ca/IHDA_Retrieval/ (Accessed February 5, 2011).

10. Statistics Canada 2006 Census data. <www12.statcan.ca/english/ Search/Search_Results.cfm?resultsLength $=10 \&$ terms $=+$ calgary + heal th+region\&geo_lev $=-1>($ Accessed February 5, 2011).

11. Fay MP, Feuer EJ. Confidence intervals for directly standardized rates: A method based on the gamma distribution. Stat Med 1997;16:791-801.

12. Newton R, Ferlay J, Beral V, Devesa SS. The epidemiology of nonHodgkin's lymphoma: Comparison of nodal and extra-nodal sites. Int J Cancer 1997;72:923-30.

13. Gurney KA, Cartwright RA, Gilman EA. Descriptive epidemiology of gastrointestinal non-Hodgkin's lymphoma in a population-based registry. Br J Cancer 1999;79:1929-34.

14. Hansen PB, Vogt KC, Skov RL, Pedersen-Bjergaard U, Jacobsen M, Ralfkiaer E. Primary gastrointestinal non-Hodgkin's lymphoma in adults: A population-based clinical and histopathologic study. J Intern Med 1998;244:71-8.

15. d'Amore F, Brincker H, Gronbaek K, et al. Non-Hodgkin's lymphoma of the gastrointestinal tract: A population-based analysis of incidence, geographic distribution, clinicopathologic presentation, features, and prognosis. J Clin Oncol 1994;12:1673-84.

16. Papaxoinis G, Papageorgiou S, Rontogianni D, et al. Primary gastrointestinal non-Hodgkin's lymphoma: A clinicopathologic study of 128 cases in Greece. A Hellenic Cooperative Oncology Group Study (HeCOG). Leuk Lymphoma 2006;47:2140-6.

17. Wotherspoon AC, Ortiz-Hidalgo C, Falzon MR, Isaacson PG. Helicobacter pylori-associated gastritis and primary B-cell gastric lymphoma. Lancet 1991;338:1175-6.

18. Saegart X, Van Cutsem E, De Hertogh G, et al. Gastric MALT lymphoma: A model of chronic inflammation-induced tumor development. Nat Rev Gastroenterol Hepatol 2010;7:336-46.

19. Huang W-T, Hsu Y-H, Yang S-F, Chuang S-S. Primary gastrointestinal follicular lymphoma: A clinicopathologic study of 13 cases from Taiwan. J Clin Gastroenterol 2008;42:997-1002.

20. Damaj G, Verkarre V, Delmer A, et al. Primary follicular lymphoma of the gastrointestinal tract: A study of 25 cases and a literature review. Ann Oncol 2003;14:623-9.

21. Shia J, Teruya-Feldstein J, Pan D, et al. Primary follicular lymphoma of the gastrointestinal tract. A clinical and pathologic study of 26 cases. Am J Surg Pathol 2002;26:216-24.

22. LeBrun DP, Kamel OW, Cleary ML, Dorfman RF, Warnke RA. Follicular lymphomas of the gastrointestinal tract. Am J Pathol 1992;140:1327-35.

23. Guermazi A, Brice P, de Kerviler E, et al. Extranodal Hodgkin disease: Spectrum of disease. Radiographics 2001;21:161-79.

24. Kodama T, Ohshima K, Nomura K, et al. Lymphomatous polyposis of the gastrointestinal tract, including mantle cell lymphoma, follicular lymphoma and mucosa-associated lymphoid tissue lymphoma. Histopathology 2005;47:467-78. 


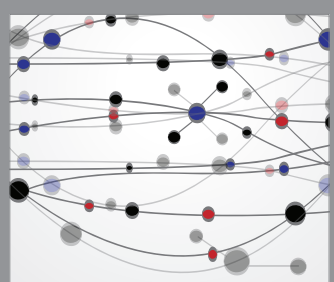

The Scientific World Journal
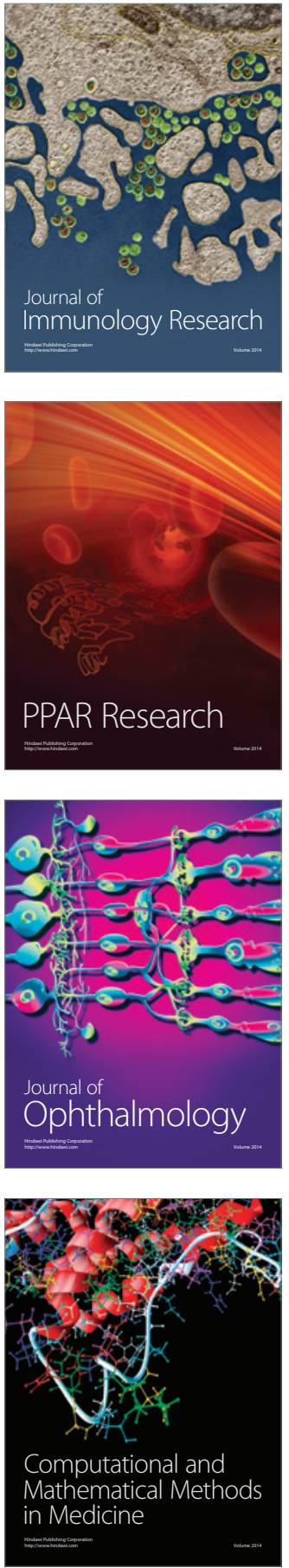

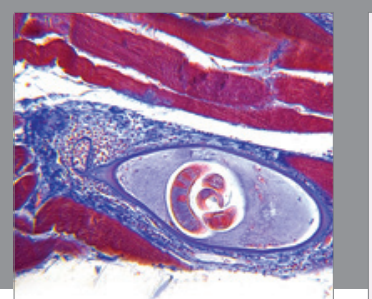

Gastroenterology Research and Practice

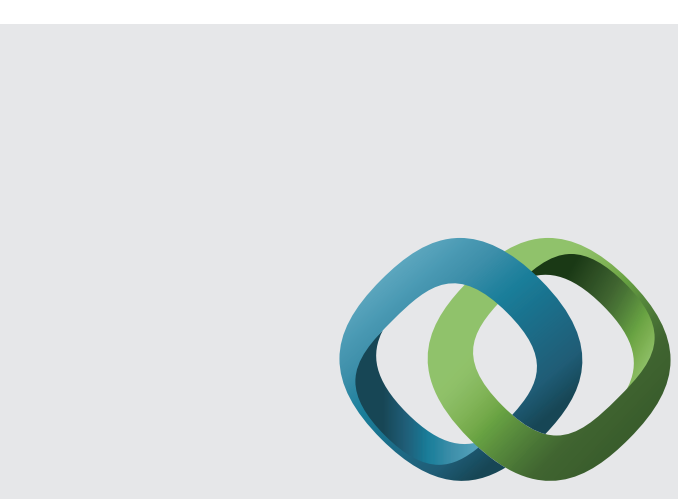

\section{Hindawi}

Submit your manuscripts at

http://www.hindawi.com
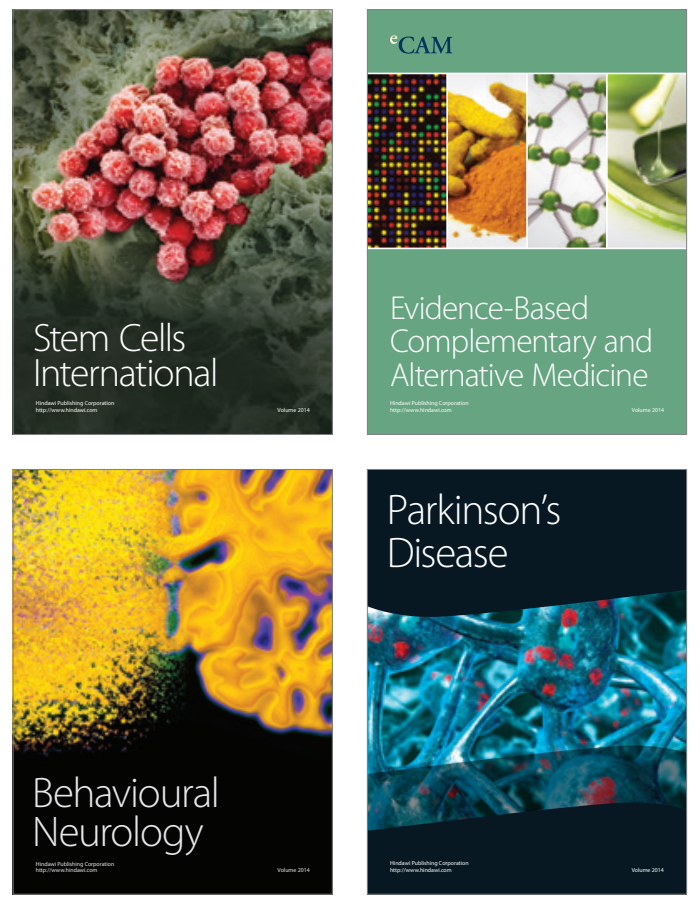
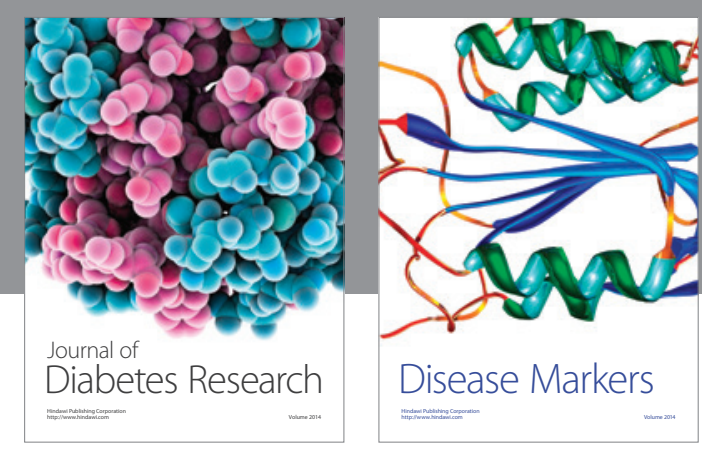

Disease Markers
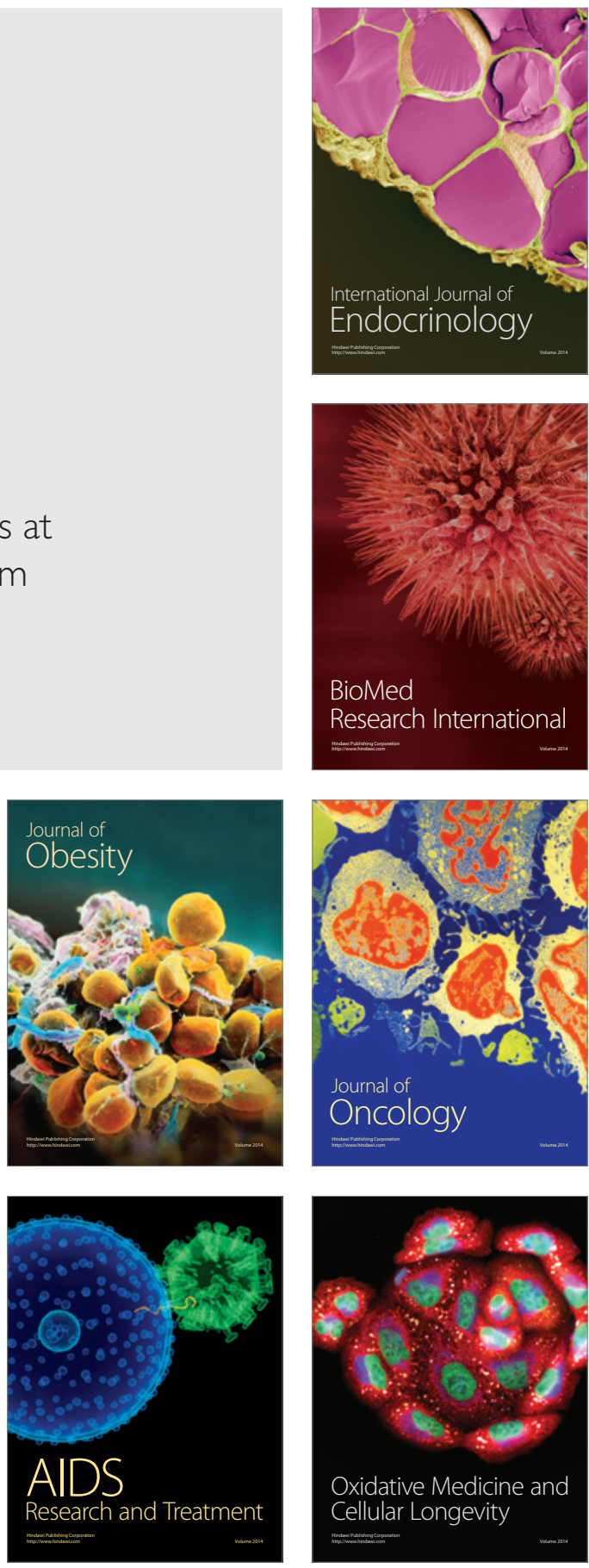